\title{
EFFECTS OF NATURALLY PRODUCED DIETARY FUSARIUM MYCOTOXINS ON WEANING PIGS
}

\author{
${ }^{1}$ Shin, S.Y., ${ }^{1}$ C. Kong, ${ }^{2}$ I.H. Kim and ${ }^{1}$ B.G. Kim \\ ${ }^{1}$ Department of Animal Science and Technology, Konkuk University, Seoul, Republic of Korea \\ ${ }^{2}$ Department of Animal Resource and Science, Dankook University, Cheonan, Choongnam, Republic of Korea
}

Received 2014-04-08; Revised 2014-04-14; Accepted 2014-04-19

\begin{abstract}
Mycotoxins reduce animal productivity and animal health. The influence of Fusarium mycotoxins in corn co-products on pig performance is an important issue in swine feed industry. This study was conducted to determine the effects of naturally produced Fusarium mycotoxins in Corn Gluten Meal (CGM) on growth performance of nursery pigs. A total 96 weaning pigs comprising 48 gilts and 48 barrows with an initial body weight of $5.08 \mathrm{~kg}(\mathrm{SD}=1.28)$ were grouped into 3 blocks in each sex by initial body weight and randomly allotted to 4 treatments in a randomized complete block design. There were 6 replicate pens per treatment and 4 pigs were housed in each pen. The 4 experimental diets mainly based on corn, CGM, dried whey and soybean meal were formulated to contain 4 concentrations of mycotoxins derived from the contaminated CGM. Diet 1 contained $32 \mu \mathrm{g} \mathrm{kg}^{-1}$ Deoxynivalenol (DON) and $6 \mu \mathrm{g} \mathrm{kg}^{-1}$ Zearalenone (ZON) and diets 2, 3 and 4 contained 532, 1,033 and 1,534 $\mathrm{g} \mathrm{kg}^{-1}$ DON and 203, 399 and $596 \mu_{\mathrm{g} \mathrm{kg}^{-1}} \mathrm{ZON}$, respectively. During the first $14 \mathrm{~d}$ of experiment, Average Daily Gain (ADG) was reduced linearly and quadratically $(\mathrm{p}<0.05)$ as concentration of dietary mycotoxin increased. Average Daily Feed Intake (ADFI) had a tendency for quadratic decrease $(p=0.059)$ with increasing dietary mycotoxin concentrations. Both ADG and ADFI from d 14 to 28 linearly decreased with increasing concentration of mycotoxins $(\mathrm{p}<0.05)$. During the overall experimental period, both ADG and ADFI linearly depressed with increasing concentration of mycotoxins $(\mathrm{p}<0.05)$. In conclusion, the current study showed that dietary Fusarium mycotoxins derived from contaminated CGM by Fusarium fungi resulted in decreased growth performance of nursery pigs. Swine nutritionists may increase nutrient concentrations of diets to partially overcome the negeative effects of Fusarium mycotoxins in corn co-products on feed intake of pigs.
\end{abstract}

Keywords: Deoxynivalenol, Zearalenone, Growth Performance, Swine

\section{INTRODUCTION}

Mycotoxins are toxic secondary metabolic byproducts of fungal genera and these toxins are known to be detrimental to animal productivity as well as animal health due to their toxicity. Among several genera of mycotoxinproducing fungi such as Aspergillus, Fusarium and Penicillium, Fusarium genus fungi commonly grow on corn, wheat and other grains (Pollmann et al., 1985; Munkvold and Desjardins, 1997) and produce several detrimental toxins such as aflatoxins, Deoxynivalenol (DON), Zearalenone (ZON) and fumonisins.
There are a number of studies that have shown the harmful effects of DON (Friend et al., 1983; Smith et al., 1997; Waché et al., 2009) and ZON (Young et al., 1981; Wang et al., 2012) on growth performance of pigs. Deoxynivalenol, also known as vomitoxin, generally damages the digestive system of pigs causing vomiting or feed refusal (Trenholm et al., 1994) while ZON disturbs the reproductive system of female pigs and consequently reduces sow performance (Döll et al., 2003; Papatsiros, 2012). Some studies carried out the experiments using corn (Young et al., 1981; Rotter et al., 1995) or wheat (Friend et al., 1983; Waché et al., 2009)

Corresponding Author: B.G. Kim, Department of Animal Science and Technology, Konkuk University, Seoul, Republic of Korea Tel: +82-2-2049-6255 
as a natural source of mycotoxin. However, there is limited information on the effects of DON and $\mathrm{ZON}$ in corn co-products contaminated by Fusarium fungi. Thus, the aim of this study was to determine detrimental effects of dietary Fusarium mycotoxins naturally contaminated in Corn Gluten Meal (CGM) on nursery pigs.

\section{MATERIALS AND METHODS}

\subsection{Feedstuffs and Diets}

Two different sources of CGM were prepared for the experiment; a CGM source that was naturally contaminated by Fusarium genus fungi and a CGM source that was not contaminated. The concentrations of DON and ZON were 6,390 and $2,483 \mu \mathrm{g} \mathrm{kg}^{-1}$, or 132 and $24 \mu \mathrm{g} \mathrm{kg}^{-1}$ in the contaminated or the control CGM, respectively.

The experimental diets were provided in a 2-phase feeding program with phase I and II diets being fed for 2 wk for each period. The diet 1 was formulated to meet or exceed nutritional requirement of weaning pigs (NRC, 2012) and was mainly based on corn, the control CGM, dried whey and soybean meal (Table 1). The mycotoxin- containing diet 2, 3 and 4 were prepared to contain 80, 160 and $240 \mathrm{~g} \mathrm{~kg}^{-1}$ of the contaminated CGM at the expense of the control CGM, respectively.

\subsection{Animals and Feeding}

The experimental procedure was approved by the Institutional Animal Care and Use Committee at Konkuk University. A total of 96 weaning pigs comprising 48 gilts and 48 barrows with an initial Body Weight (BW) of $5.08 \mathrm{~kg}(\mathrm{SD}=1.28)$ was used in the experiment. Pigs were grouped into 3 blocks in each gender based on initial $\mathrm{BW}$ and randomly allotted to 4 treatments in a randomized complete block design. There were 6 replicate pens per treatment and 4 pigs were housed in each pen. The pens were equipped with a two-hole stainless steel feeder, a nipple drinker and fully slatted plastic floor. Diets and water were freely available for 28 $\mathrm{d}$ of the entire experimental period.

Individual $\mathrm{BW}$ and feed consumption were measured on a pen basis on d 14 and 28. Based on these records, the growth performance including Average Daily Gain (ADG), Average Daily Feed Intake (ADFI) and gain to feed ratio $(\mathrm{G}: \mathrm{F})$ were calculated.

Table 1. Ingredient composition and amount of mycotoxins of experimental diets (as-fed basis)

\begin{tabular}{|c|c|c|c|c|c|c|c|c|}
\hline \multirow[b]{2}{*}{ Ingredient $^{\mathrm{a}}(\mathrm{g} / \mathrm{kg})$} & \multicolumn{4}{|l|}{ Phase I } & \multicolumn{4}{|l|}{ Phase II } \\
\hline & Diet 1 & Diet 2 & Diet 3 & Diet 4 & Diet 1 & Diet 2 & Diet 3 & Diet 4 \\
\hline Corn & 387.6 & 387.6 & 387.6 & 387.6 & 499.5 & 499.5 & 499.5 & 499.5 \\
\hline CGM, contaminated & 0.0 & 80.0 & 160.0 & 240.0 & 0.0 & 80.0 & 160.0 & 240.0 \\
\hline CGM, control & 240.0 & 160.0 & 80.0 & 0.0 & 240.0 & 160.0 & 80.0 & 0.0 \\
\hline Dried whey & 200.0 & 200.0 & 200.0 & 200.0 & 100.0 & 100.0 & 100.0 & 100.0 \\
\hline Soybean meal & 100.0 & 100.0 & 100.0 & 100.0 & 90.0 & 90.0 & 90.0 & 90.0 \\
\hline SDPP & 40.0 & 40.0 & 40.0 & 40.0 & 40.0 & 40.0 & 40.0 & 40.0 \\
\hline Limestone & 13.5 & 13.5 & 13.5 & 13.5 & 13.0 & 13.0 & 13.0 & 13.0 \\
\hline Dicalcium phosphate & 6.5 & 6.5 & 6.5 & 6.5 & 5.5 & 5.5 & 5.5 & 5.5 \\
\hline L-Lysine-HCl & 5.4 & 5.4 & 5.4 & 5.4 & 5.0 & 5.0 & 5.0 & 5.0 \\
\hline Salt & 4.0 & 4.0 & 4.0 & 4.0 & 4.0 & 4.0 & 4.0 & 4.0 \\
\hline Mineral premix ${ }^{b}$ & 2.0 & 2.0 & 2.0 & 2.0 & 2.0 & 2.0 & 2.0 & 2.0 \\
\hline Vitamin premix ${ }^{c}$ & 1.0 & 1.0 & 1.0 & 1.0 & 1.0 & 1.0 & 1.0 & 1.0 \\
\hline Total & $1,000.0$ & $1,000.0$ & $1,000.0$ & $1,000.0$ & $1,000.0$ & $1,000.0$ & $1,000.0$ & $1,000.0$ \\
\hline \multicolumn{9}{|l|}{$\operatorname{Mycotoxin}^{\mathrm{d}}(\mu \mathrm{g} / \mathrm{kg})$} \\
\hline DON & 32.0 & 532.0 & $1,033.0$ & $1,534.0$ & 32.0 & 532.0 & $1,033.0$ & $1,534.0$ \\
\hline $\mathrm{ZON}$ & 6.0 & 203.0 & 399.0 & 596.0 & 6.0 & 203.0 & 399.0 & 596.0 \\
\hline
\end{tabular}

${ }^{\mathrm{a}} \mathrm{CGM}=$ Corn Gluten Meal; SDPP = Spray Dried Plasma Protein

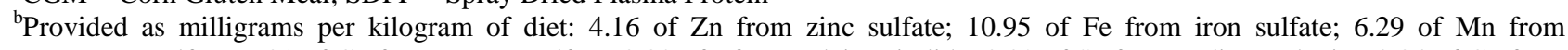
manganese sulfate; 6.31 of $\mathrm{Cu}$ from copper sulfate; 0.08 of I from calcium iodide; 0.02 of Se from sodium selenite; 0.04 of Co from cobalt sulfate

${ }^{\mathrm{c}}$ Provided per kilogram of diet: 25,000 IU of vitamin A; $40 \mathrm{IU}$ of vitamin E; $85 \mathrm{mg}$ of vitamin C; $40 \mathrm{mg}$ of niacin

${ }^{\mathrm{d} C}$ Calculated value in micrograms per kilogram of diet based on analyzed mycotoxin concentration in CGM 


\subsection{Mycotoxin Analysis}

Analyses of AFLatoxin (AFL), DON, Fumonisin B1 (FB1), OchraToxin A (OTA) and ZON were carried out by HPLC at Romer Labs (Romer Labs Singapore Pte Ltd, Singapore). Two major mycotoxins, DON and $\mathrm{ZON}$, were analyzed by using enzyme-linked immunosorbent assay (ELISA) kits (AgraQuant ${ }^{\circledR}$, Romer Labs Inc. Singapore) which had a detection limits at 200 and $20 \mu \mathrm{g} \mathrm{kg}^{1}$ for DON and ZON, respectively.

\subsection{Statistical Analysis}

Data were analyzed by analysis of variance using generalized linear model procedure (SAS Inst. Inc., Cary, NC). The model included dietary treatment, sex and block as independent variable. Least squares means of each treatment were calculated for each variable. Orthogonal polynomial contrasts were used to determine linear and quadratic effects of increasing dietary mycotoxin concentrations on the growth performance of pigs. A pen was the experimental unit and the statistical significance was declared at an alpha-level of 0.05 . Probability values between 0.05 and 0.10 were considered tendency towards a difference.

\section{RESULTS}

The mycotoxin concentrations in the control CGM and the contaminated CGM are presented in Table 2. The concentrations of AFL in both CGM samples were below $1 \mu \mathrm{g} \mathrm{kg}^{-1}$ whereas the other toxin contents were greater in the contaminated CGM than in the control CGM. The concentration of DON and ZON in the contaminated CGM determined by ELISA method fairly corresponded to values derived from HPLC method.

Table 2. Analyzed concentration of mycotoxins from 2 sources of corn gluten meal (as-is basis)

\begin{tabular}{lrrrr}
\hline & \multicolumn{2}{c}{ CGM, control } & \multicolumn{2}{c}{ CGM, contaminated } \\
& ---------- & ----- \\
Item $^{\text {a }}$ & HPLC $^{\mathrm{b}}$ & ELISA & HPLC & ELISA \\
\hline DON & 132 & 105 & 6,390 & 4,441 \\
ZON & 24 & 6 & 2,483 & 2,998 \\
FB1 & 450 & $-{ }^{c}$ & 2,911 & - \\
OTA & 14 & - & 24 & - \\
AFL & $<1$ & - & $<1$ & - \\
\hline
\end{tabular}

${ }^{\mathrm{a}} \mu \mathrm{g} \mathrm{kg}^{-1} ;$ DON $=$ deoxynivalenol; $\mathrm{ZON}=$ zearalenone; FB1 = fumonisin $\mathrm{B} 1$; OTA = ochratoxin; $\mathrm{AFL}=$ aflatoxin.

${ }^{\mathrm{b}} \mathrm{HPLC}=$ high performance liquid chromatography; ELISA = enzyme-linked immunosorbent assay.

${ }^{\mathrm{c}}$ Not analyzed.

Table 3. Growth performance of pigs fed diets containing 4 concentrations of mycotoxinsa

\begin{tabular}{|c|c|c|c|c|c|c|c|}
\hline \multirow[b]{2}{*}{ Item } & \multicolumn{4}{|c|}{ Dietary number } & \multirow[b]{2}{*}{ SEM $^{\mathrm{b}}$} & \multicolumn{2}{|l|}{$\mathrm{P}$-value } \\
\hline & 1 & 2 & 3 & 4 & & Linear & Quadratic \\
\hline \multicolumn{8}{|c|}{$\operatorname{Mycotoxin}^{\mathrm{c}}\left(\mu \mathrm{g} \mathrm{kg}^{-1}\right)$} \\
\hline Deoxynivalenl & 32.000 & 532.000 & $1,033.000$ & $1,534.000$ & & & \\
\hline Zearalenone & 6.000 & 203.000 & 399.000 & 596.000 & & & \\
\hline \multicolumn{8}{|l|}{ Body weight (kg) } \\
\hline D 0 & 5.120 & 5.040 & 5.130 & 4.970 & 0.09 & 0.391 & 0.689 \\
\hline D 14 & 11.610 & 11.280 & 11.200 & 11.080 & 0.08 & 0.006 & 0.198 \\
\hline D 28 & 15.130 & 14.660 & 14.460 & 14.320 & 0.11 & $<0.001$ & 0.154 \\
\hline \multicolumn{8}{|l|}{ Day 0 to 14} \\
\hline ADG, $\mathrm{g} \mathrm{d}^{-1}$ & 273.000 & 259.000 & 250.000 & 257.000 & 3.96 & 0.005 & 0.018 \\
\hline ADFI, $\mathrm{g} \mathrm{d}^{-1}$ & 336.000 & 319.000 & 321.000 & 324.000 & 4.86 & 0.134 & 0.059 \\
\hline $\begin{array}{l}\text { Gain:feed, } \mathrm{g} \mathrm{g}^{-1} \\
\text { Day } 14 \text { to } 28\end{array}$ & 0.814 & 0.814 & 0.782 & \multicolumn{3}{|c|}{ Day 14 to 28} & 0.701 \\
\hline ADG, $\mathrm{g} \mathrm{d}^{-1}$ & 442.000 & 428.000 & 416.000 & 411.000 & 4.03 & $<0.001$ & 0.310 \\
\hline ADFI, $\mathrm{g} \mathrm{d}^{-1}$ & 546.000 & 539.000 & 531.000 & 524.000 & 5.37 & 0.007 & 0.923 \\
\hline Gain:feed, $\mathrm{g} \mathrm{g}^{-1}$ & 0.809 & 0.794 & 0.784 & 0.784 & 0.01 & 0.032 & 0.377 \\
\hline \multicolumn{8}{|l|}{ Day 0 to 28} \\
\hline $\mathrm{ADG}, \mathrm{g} \mathrm{d}^{-1}$ & 357.000 & 3440.000 & 333.000 & 334.000 & 2.66 & $<0.001$ & 0.014 \\
\hline ADFI, $\mathrm{g} \mathrm{d}^{-1}$ & 441.000 & 429.000 & 426.000 & 424.000 & 3.48 & 0.003 & 0.154 \\
\hline Gain:feed, $\mathrm{g} \mathrm{g}^{-1}$ & 0.810 & 0.801 & 0.783 & 0.788 & 0.01 & 0.021 & 0.356 \\
\hline
\end{tabular}

${ }^{\mathrm{a}}$ Each least squares of means represent 6 pens of 4 pigs per pen.

${ }^{\mathrm{b}} \mathrm{Standard}$ error of the means

${ }^{\mathrm{c}}$ Calculated value in micrograms per kilogram of diet based on analyzed mycotoxin concentration in corn germ meal 
Dietary Fusarium mycotoxins negatively affected growth performance of weaning pigs (Table 3 ). During the first $14 \mathrm{~d}$ of the experiment, ADG decreased linearly and quadratically $(\mathrm{p}<0.05)$ as mycotoxin concentration increased.The ADFI tended to be affected by dietary treatments (quadratic, $\mathrm{p}=$ $0.059)$. During d 14 to 28 , ADG ( $<<0.001)$, ADFI ( $\mathrm{p}=$ $0.007)$ and gain: Feed $(p=0.032)$ decreased linearly as mycotoxin concentrations increased, showing that there were reductions of ADG, ADFI and gain: Feed by $7.0,4.0$ and $3.1 \%$, respectively, in the highest concentration compared with the lowest concentration of mycotoxins. During the overall period, ADG, ADFI and gain: Feed decreased linearly $(\mathrm{p}<0.05)$ as mycotoxin concentration increased.

\section{DISCUSSION}

In the current study, DON and ZON were major mycotoxins in the contaminated CGM. European Union commission suggests the guidance values of DON, ZON, OTA and FB1 for typical swine diets at 0.9, 0.25, 0.05 and $5 \mathrm{mg} \mathrm{kg}^{-1}$, respectively (EC, 2006). This indicates that the concentrations of both DON and $\mathrm{ZON}$ in diet 3 and 4 used in the present experiment were above the guidance values of (EC, 2006).

Fumonisin B1 in the ingredients used in the current study also existed at the concentration of 2,911 and 450 $\mu \mathrm{g} \mathrm{kg}$ for the contaminated and control CGM, respectively and concentration was diluted at 108, 305, 502 and $699 \mathrm{~g} \mathrm{~kg}^{-1}$ in diets $1,2,3$ and 4, respectively. According to Zomborszky-Kovács et al. (2002), 1,000 $\mu \mathrm{g} \mathrm{kg}^{-1}$ of FB1 was considered a tolerable concentration for pigs, thus the concentration of FB1 in the current study would not be the major cause for the reduction in growth performance of pigs.

The overall reductions in ADG and G: $F$ of pigs fed diet 4 compared with diet 1 were 6.4 and $2.7 \%$, respectively. The respective values were within ranges that were predicted with collective data from the literature (Mok et al., 2013). Decreased ADG observed in the present experiment appears to be mainly affected by the reduced feed intake but not directly by mycotoxins. Andretta et al. (2012) also suggested that the degeneration of weaning pigs' growth was due to reduced feed intake, but not by presence of mycotoxin per se. In agreement, several reports have been shown that dietary DON adversely affected growth performance of pigs by reducing feed intake (Young et al., 1983; Smith et al., 1997; Waché et al., 2009). Reduced feed intake caused by DON would be attributed to reduced hepatic protein synthesis which causes raised blood tryptophan, a precursor of serotonin and subsequently elevated brain serotonin concentrations (Díaz-Llano and Smith, 2006). The elevated concentration of serotonin consequently would be responsible for anorexic effects of DON (Leathwood, 1987).

In contrast, the effects of ZON on ADFI of pigs were not always significant. James and Smith (1982) reported that ZON up to $40 \mathrm{mg} \mathrm{kg}^{-1}$ did not affect feed consumption of pigs and this result was in agreement with other reports that suggested no adverse effect of $\mathrm{ZON}$ on feed intake when gilts or weaning pigs were fed 1 to $2 \mathrm{mg} \mathrm{kg}^{-1}$ of ZON (Rainey et al., 1990; Jiang et al., 2012). In addition, dietary ZON may negatively affect feed intake when combined with dietary DON, but not ZON solely (Young et al., 1981; Williams and Blaney, 1994).

\section{CONCLUSION}

In conclusion, the present study showed that dietary Fusarium mycotoxins derived from contaminated CGM by Fusarium fungi resulted in decreased the growth performance of pigs which could be mainly attributed to the negative effects of DON on feed consumption of pigs. The mechanisms contributing the main action in DON are still unclear. Further research is warranted to elucidate the mode of actions by which dietary DON reduces feed intake.

\section{ACKNOWLEDGEMENT}

The researchers are grateful for the support by Rural Development Administration (Suwon, Republic of Korea; PJ008405). This study resulted from the Konkuk University research support program.

\section{REFERENCES}

Andretta, I., M. Kipper, C.R. Lehnen, L. Hauschild and M.M. Vale et al., 2012. Meta-analytical study of productive and nutritional interactions of mycotoxins in growing pigs. Animal, 6: 1476-1482. DOI: $10.1017 / \mathrm{S} 1751731111002278$

Díaz-Llano, G. and T.K. Smith, 2006. Effects of feeding grains naturally contaminated with Fusarium mycotoxins with and without a polymeric glucomannan mycotoxin adsorbent on reproductive performance and serum chemistry of pregnant gilts. J. Anim. Sci., 84: 2361-2366. DOI: 10.2527/jas.2005-699

Döll, S., S. Dänicke, K.H. Ueberschär, H. Valenta and G. Flachowsky et al., 2003. Effects of graded levels of fusarium toxin contaminated maize in diets for female weaned piglets. Archives Anim. Nut., 63: 689-698. DOI: 10.1080/0003942031000160768 
EC, 2006. Commission Recommendation of 17 August 2006 on the presence of deoxynivalenol, zearalenone, ochratoxin A, T-2 and HT-2 and fumonisins in products intended for animal feeding. 2006/576/EC. European Community.

Friend, D.W., H.L. Trenholm, P.S. Fiser, B.K. Thompson and K.E. Hartin et al., 1983. Effect on dam performance and fetal development of deoxynivalenol (vomitoxin) contaminated wheat in the diet of pregnant gilts. Canadian J. Anim. Sci., 63: 689-698. DOI: 10.4141/cjas83-078.

James, L.J. and T.K. Smith, 1982. Effect of dietary alfalfa on zearalenone toxicity and metabolism in rats and swine. J. Anim. Sci., 55: 110-118. PMID: 6214539

Jiang, S.Z., Z.B. Yang, W.R. Yang, S.J. Wang and Y. Wang et al., 2012. Effect of purified zearalenone with or without modified montmorillonite on nutrient availability, genital organs and serum hormones in post-weaning piglets. Livestock Sci., 144: 110-118. DOI: 10.1016/j.livsci.2011.11.004.

Leathwood, D., 1987. Tryptophan availability and serotonin synthesis. Proc. Nut. Society, 46: 143-156. DOI: $10.1079 /$ PNS19870018

Mok, C.H., S.Y. Shin and B.G. Kim, 2013. Aflatoxin, deoxynivalenol and zearalenone in swine diets: Predictions on growth performance. Revista Colombiana de Ciencias Pecuarias, 26: 243-254.

Munkvold, G.P. and A.E. Desjardins, 1997. Fumonisins in maize: Can we reduce their occurrence. Plant Dis., $\quad$ 81: 556-565. DOI: 10.1094/PDIS.1997.81.6.556

NRC, 2012. Nutrient Requirements of Swine. 11th Edn., National Academic Press, Washington, DC., USA. ISBN: 978-0-309-22423-9.

Papatsiros, V.G., 2012. The splay leg syndrome in piglets: A Review. Am. J. Anim. Vet. Sci., 7: 80-83. DOI: 10.3844/ajavsp.2012.80.83

Pollmann, D.S., B.A. Koch, L.M. Seitz, H.E. Mohr and G.A. Kennedy, 1985. Deoxynivalenol-contaminated wheat in swine diets. J. Anim. Sci., 60: 239-247. PMID: 3972745

Rainey, M.R., R.C. Tubbs, L.W. Bennett and N.M. Cox, 1990. Prepubertal exposure to dietary zearalenone alters hypothalamo-hypophysial function but does not impair postpubertal reproductive function of gilts. J. Anim. Sci., 68: 2015-2022. PMID: 2143505
Rotter, B.A., B.K. Thompson and M. Lessard, 1995. Effects of deoxynivalenol-contaminated diet on performance and blood parameters in growing swine. Canadian J. Anim. Sci., 75: 297-302. DOI: 10.4141/cjas95-046.

Smith, T.K., E.C. McMillan and J.B. Castillo, 1997. Effect of feeding blends of Fusarium mycotoxincontaminated grains containing deoxynivalenol and fusaric acid on growth and feed consumption of immature swine. J. Anim. Sci., 75: 2184-2191. PMID: 9263067

Trenholm, H.L., B.C. Foster, L.L. Charmley, B.K. Thompson and M.A. Albassam et al., 1994. Effects of feeding diets containing Fusarium (naturally) contaminated wheat or pure Deoxynivalenol (DON) in growing pigs. Canadian J. Anim. Sci., 74: 361369. DOI: 10.4141/cjas94-049

Waché, Y.J., C. Valat, G. Postollec, S. Bougeard and P. Fravalo et al., 2009. Impact of deoxynivalenol on the intestinal microflora of pigs. Int. J. Molecular Sci., 10: 1-17. DOI: 10.3390/ijms10010001

Wang, J.P., F. Chi and I.H. Kim, 2012. Effects of montmorillonite clay on growth performance, nutrient digestibility, vulva size, faecal microflora and oxidative stress in weaning gilts challenged with zearalenone. Anim. Feed Sci. Technol., 178: 158166. DOI:10.1016/j.anifeedsci.2012.09.004

Williams, K.C. and B.J. Blaney, 1994. Effect of the mycotoxins, nivalenol and zearalenone, in maize naturally infected with Fusarium graminearum on the performance of growing and pregnant pigs. Aus. J. Agric. Res., 45: 1265-1279. DOI: 10.1071/AR9941265

Young, L.G., L. Mcgirr, V.E. Valli, J.H. Lumsden and A. Lun et al., 1983. Vomitoxin in corn fed to young pigs. J. Anim. Sci., 57: 655-664. PMID: 6630099

Young, L.G., R.F. Vesonder, H.S. Funnell, I. Simons and B. Wilcock et al., 1981. Moldy corn in diets of swine. J. Anim. Sci., 52: 1312-1318.

Zomborszky-Kovács, M., F. Vetési, P. Horn, I. Repa and F. Kovács et al., 2002. Effects of prolonged exposure to low-dose fumonisin B1 in pigs. J. Vet. Med. Series B., 49: 197-201. DOI: 10.1046/j.14390450.2002.00519.x 